\title{
Margaret McCartney: Doctors and families must be able to work together for safer care
}

\author{
Margaret McCartney general practitioner
}

Glasgow

A little boy, Jack Adcock, is dead. This is horrendous, and accounts of the background to the case clearly show mistakes and shortcomings that could and should have been avoided. But how?

Jack's treatment included clinical mistakes and numerous systemic ones, particularly regarding staff absence and IT systems. This was the "Swiss cheese" model writ large and fatal: the holes in the system aligned and let tragedy happen.

The overwhelming feeling among many doctors reading accounts of the case background ${ }^{1}$ is, "There but for the grace of God go I." There's no suggestion that Hadiza Bawa-Garba was doing anything except working hard, with two doctors down, covering six wards on four floors, and providing medical advice to other professional groups. ${ }^{2}$

Will striking her off the medical register ensure that a death like Jack's can't happen again? I don't believe so. Professional regulation and accountability are vital. So, too, is patient safety. But the way we administer the two are often at odds.

There must be a better way to investigate deaths-one that examines human factors and systemic problems

The regulation of doctors is an adversarial system that seeks to deliver blame and sanctions to individuals. Blame and sanctions clearly have their place. But it's taken a long time for us to regard human factors as the problem in many medical errors and safer systems as the solution-as well as outstanding efforts by people such as Martin Bromiley, who founded the Clinical Human Factors Group, ${ }^{3}$ a charitable trust that promotes best practice around human factors. As the group says, "A safer, more reliable and efficient NHS will remain a pipe dream until we create a culture where human error is seen as normal, inevitable, and as a source of important learning." ${ }^{4}$

As Bawa-Garba's reflective notes were used as evidence against her in court, such a culture is unlikely any time soon. And the words of Mr Justice Ouseley, giving the leading judgment on the case in the High Court, are of particular concern: "There was no suggestion, unwelcome and stressful though the failings around her were, and with the workload she had, that this was something she had not been trained to cope with or was something wholly out of the ordinary for a year 6 trainee, not far off consultancy, to have to cope with, without making such serious errors." 5 This seems to imply that doctors can be trained to have limitless capabilities. None of us can be.

There must be a better way to investigate deaths-one that examines human factors and systemic problems, which doesn't only insist on evidence based change but can also command the confidence of bereaved families, as well as honesty from the medical profession.

A culture of fear is looming, but it needn't be this way. Doctors, patients, and families should be able to work together to make systems safer. We need to move forwards, but this judgment risks taking us far back.

Competing interests: See www.bmj.com/about-bmj/freelancecontributors/margaret-mccartney.

Provenance and peer review: Commissioned; not externally peer reviewed.

Follow Margaret on Twitter, @mgtmccartney 1 Cohen D. Back to blame: the Bawa-Garba case and the patient safety agenda. BMJ
2017;359:j5534. doi:10.1136/bmj.j553429187347
54000doctors.org. An account by concerned UK paediatric consultants of the tragic events
surrounding the GMC action against Dr Bawa-Garba. http://www.54000doctors.org/blogs/
an-account-by-concerned-uk-paediatric-consultants-of-the-tragic-events-surrounding-the-
gmc-action-against-dr-bawa-garba.html.
$3 \quad$ Clinical Human Factors Group. Martin Bromiley. http://chfg.org/chair/martin-bromiley/.
$4 \quad$ Clinical Human Factors Group. Manifesto. http://chfg.org/about-us/manifesto/.
$5 \quad$ Dyer C. Paediatrician convicted of manslaughter must be erased from register, rules High
Court. BMJ 2018;360:k417. doi:10.1136/bmj.k41729374024
Published by the BMJ Publishing Group Limited. For permission to use (where not already
granted under a licence) please go to http://group.bmj.com/group/rights-licensing/ permissions 